\section{Foreign Body: \\ An Unreported Association with Mucosectomy Scar}

A 44-year-old man with a history of alcohol abuse and smoking was receiving follow-up at our hospital owing to chronic pancreatitis. As he was suffering vague dyspeptic symptoms, he underwent esophagogastroduodenoscopy. He had not previously undergone any form of surgery. The endoscopic examination identified a slightly depressed hyperemic esophageal lesion, $1.5 \mathrm{~cm}$ in diameter, $31 \mathrm{~cm}$ distal to the superior dental arcade, which did not stain on exposure to Lugol's solution (Figure 1). Histopathological examination of the endoscopic biopsies revealed a superficial squamous-cell carcinoma, with areas of high-grade dysplasia. The integrity of the submucosal layer was confirmed by endoscopic ultrasonography. Endoscopic mucosectomy was carried out as a curative treatment, as described in the recent literature [1], apparently with initial success. Histopathological examination of the tissue removed during the mucosectomy showed that the cancer was restricted to the mucosal layer.

A check-up endoscopy was carried out three months later; the patient was completely asymptomatic. The examination revealed a white, regular scar in the area corresponding to the previous mucosectomy (Figure 2). Biopsies carried out to investigate the scar revealed a foreign body - a piece of cotton thread $15 \mathrm{~cm}$ long (Figure 3).

Foreign bodies in the esophagus are a common problem, mainly in children. Adults are less likely to swallow undigestible items deliberately, with the exception of a few groups in which there is clearly a

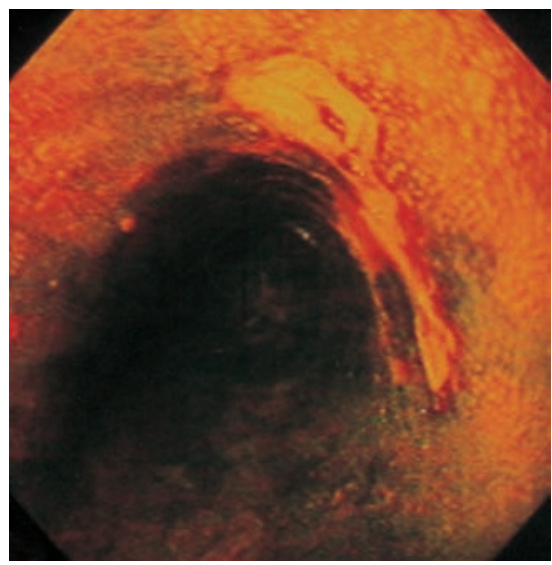

Figure 1 A slightly depressed, hyperemic early esophageal cancer. Lugol staining was negative

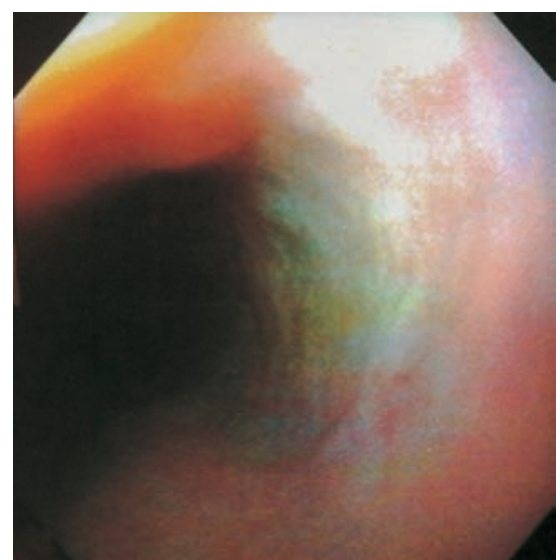

Figure 2 Check-up endoscopy at the site of the previous mucosectomy

high risk - individuals with psychiatric illness, abusers of drugs or alcohol (as in this patient), and prison inmates. Esophageal impaction occurs more frequently in adults when there is pathological narrowing of the esophagus, as in peptic stricture or distal esophageal ring [2]. Cancer is rarely associated with foreign-body impaction [3]. It has been reported that mucosectomy may be associated with severe complications such as hemorrhage or perforation, in approximately $6.8 \%$ of cases. However, a search of the literature failed to identify any previous reports of cases of reepithelialization over a foreign body after mucosectomy.

\section{F. G. Viana ${ }^{1}$, J. E. Brunaldi ${ }^{2}$,}

J. L. P. Módena ${ }^{2}$

${ }^{1}$ Dept. of Internal Medicine,

Division of Gastroenterology

${ }^{2}$ Dept. of Surgery and Traumatology,

Digestive Endoscopy Section,

Faculty of Medicine of Ribeirão Preto,

University of São Paulo, Ribeirão Preto, Brazil

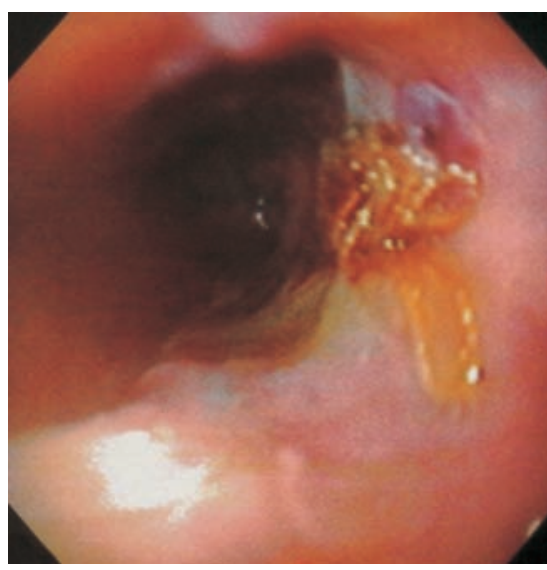

Figure 3 The mucosectomy site after biopsy. Note the cotton thread that was underneath the reepithelialized mucosa

\section{References}

${ }^{1}$ Lambert R. Endoscopy mucosectomy: an alternative treatment for superficial esophageal cancer. Recent Results Cancer Res 2000; 155: 183-192

${ }^{2}$ Yeaton P, Peura DA. Foreign bodies. In: Castell DO, Richter JE (eds). The esophagus. Philadelphia: Lippincott-Raven, 1999; 3rd ed.: 335-348

${ }^{3}$ Nandi P, Ong GB. Foreign body in the oesophagus: review of 2394 cases. $\mathrm{Br} J$ Surg 1978; 65: 5-9

\section{Corresponding Author}

C. F. G. Viana, M.D

Departamento de Clínica Médica

Hospital das Clínicas

Faculdade de Medicina

Ribeirão Preto-USP

Campus Universitário

14048-900 Ribeirão Preto, SP

Brazil

Fax: + 55-16-633-6695

E-mail: cyntiafgv@usa.net 